\title{
Aggregation and Characterization of ZnO Nano Particles Using Laser Ablation Technique in Ethanol
}

\author{
Wisam J. Aziz, M.A.Abid and Hanan Kh. Mutlk \\ Department of Physics, College of Science, Al-Mustansiriyah-University, Baghdad-Iraq. \\ Corresponding Author: hanan2000719@yahoo.com.
}

\begin{abstract}
In this work, $\mathrm{ZnO}$ nanoparticles were snthyesis using pulse laser ablation of zinc target (purity of 99.99\%) immersed in ethanol with wave length of Nd:YAG laser (532 nm) operating at different laser energies $(700,800,900 \mathrm{~mJ})$ with $1 \mathrm{~Hz}$ and (2000) pulse. A matching of the observed and standard (hkl) planes confirmed that the product is $\mathrm{ZnO}$ having a polycrystalline in nature with hexgonal structure perferention in (101) direction.

FESEM images showed that NPs have different morphologies and not uniform consist of many small irregular nanoparticles. The surface structure, in the energy $700 \mathrm{~mJ}$ has been more uniform compared with others energy. [DOI: 10.22401/JNUS.20.4.06]
\end{abstract}

Keywords: ZnO nanoparticles, X-ray diffraction, Morphology, PLA, FESEM.

\section{Introduction}

The Pulse laser ablation is typical example of top-down approach to fabricate nanoparticles [1]. The Nanoparticles have great scientific interest as they are effectively a bridge between bulk materials and atomic or molecular structures, at this size, physical, chemical and biological properties of substance are different in compared with properties in the micrometer and larger scales [2]. The characteristitics of new, research have found that they can develop materials, devices and systems that are superior to those in use today, but smaller in size such as laser ablation in liquid and chemical etching [3]. In the period previous, special attention has been devoted to the morphology, as $\mathrm{ZnO}$ can form different nanostructures, such as nanobelts, nanoribbons, nanowires, nanotubes, nanohelixes, nanorods and Nanoparticles [4].

\section{Experimental procedure}

The zinc target (purity of 99.99\%) has been immersed in ethanol and fixed at bottom of glass vessel container with different laser energies $(700,800,900 \mathrm{~mJ})$. The number of pulse laser which used are (2000) pulses. Nd:YAG laser system (type HUAFEI) providing $532 \mathrm{~nm}$ wavelength with pulse duration was $10 \mathrm{~ns}$, repetition rate $1 \mathrm{~Hz}$ and effective beam diameter $4.8 \mathrm{~mm}$. When ablation of zinc target, $\mathrm{ZnO}$ nanoparticles colloidal were formed in liquid. In order to make solution homogeneity the colloidal dispersed with ultrasonically for $15 \mathrm{~min}$ and magnetic stirrer for 30 minutes. lather the, solution drop casting on clean glass substrate which put on hot plate stirrer at temperature $\left(85^{\circ} \mathrm{C}\right)$ for 45 minute. Fig.(1) shows the experimental setup of pulse laser ablation:

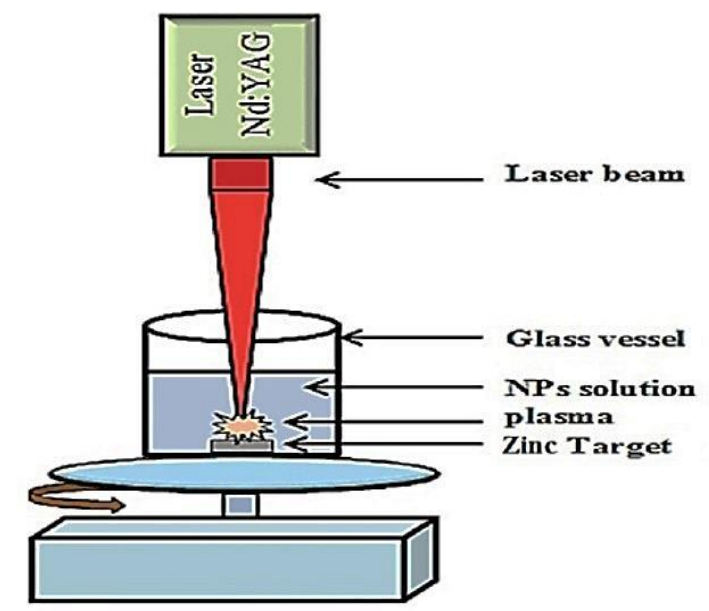

Fig.(1): Experimental setup of noanoparticles synthesis by PLA method.

\section{Results and Discussion}

In differaction in Fig.(2), the XRD patterns of $\mathrm{ZnO}$ thin film contain five main peaks at diffraction angle $31.77^{\circ}, 34.32^{\circ}, 36.32^{\circ}, 47.06^{\circ}$ and $56.56^{\circ}, 62.52^{\circ}$ corresponding to (100), (002), (101), (110),(103) and (102) planes. The strong and narrow peaks may be ascribed to the preferential growth along (101) plane of $\mathrm{ZnO}$. The crystal size of the crystalline 
material has an important effect in determining the properties of the material and can be of the (FWHM) which is given to (Debye-Scherrer relation):

$$
D_{g}=\frac{0.9 \lambda}{\beta \cos \theta_{B}}
$$

Where Dg: is the crystal size, 0.9 is the Scherrer constant, $\lambda$ : is the $\mathrm{X}$-ray wavelength, $\beta$ : is the full width ahalf maximum and $\theta_{B}$ : is the Bragg diffraction angle.

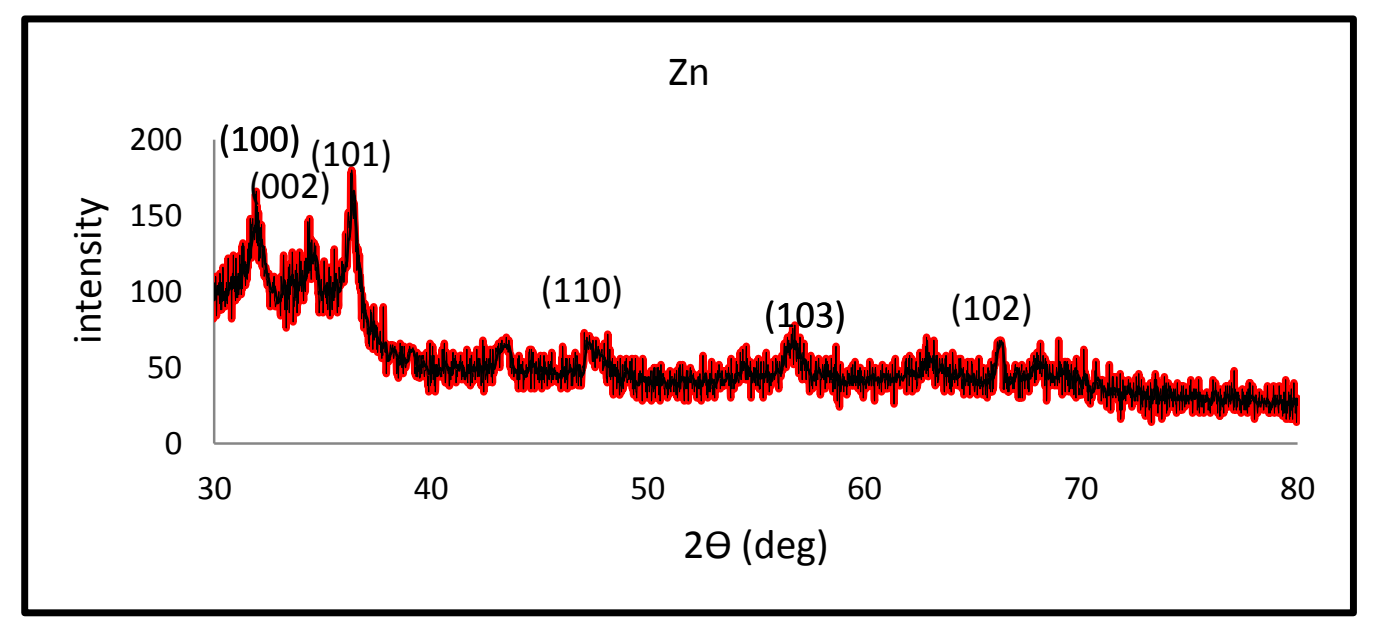

Fig.(2) : XRD pattern of Zn target.

The strong and narrow peaks may be ascribed to the preferential growth along (101) plane of $\mathrm{ZnO}$. The results revealed that the strain and dislocation density are decrease with increasing the grain size. The crystal size of the crystalline material has an important effect in determining the properties of the material. The d-value of nano crystalline $\mathrm{ZnO}$ as given in Table (1), crystal size (D) in $\mathrm{nm}$ for a knowing X-ray wavelength $\Theta$ at a diffraction angle $\Theta$ of $\mathrm{ZnO}$ nanoparticles is calculated by using Scherrer formula as given in equation (1), the peak width of a strong diffraction plane were calculated and listed in Table (1).

Fig.(3) show that the X-ray differaction obtained through the laser ablation to zinc target in ethanol solution deposition on a glass substrate with energies (700, 800 and $900 \mathrm{~mJ})$ and pulses of laser fixed at 2000 pulses. This figure show that the peakesat diffraction angle $\left(31.82^{\circ}, 34.6^{\circ} 2,36^{\circ} .62,47.48^{\circ}, 56.36^{\circ}\right.$ but $\left.62.88^{\circ}\right)$ at films prepared at $700 \mathrm{~mJ}$ bu for at energy films prepare at energy of $800 \mathrm{~mJ}$ energy was $800 \mathrm{~mJ}$ peak diffraction angle for are $31.14^{\circ}, 34.22,36^{\circ} .22,47.42^{\circ}, 56.48^{\circ}$ and $62.02^{\circ}$ ) while in energy $900 \mathrm{~mJ}$ the peakes at anglse are a $\left(31.68^{\circ}, 34\right.$ and $\left.36^{\circ} .08\right)$, through the diffraction test dispersion (X-ray) found its kind multi gelling by the presence of a number of vectices of acute it the direction (101) as show in Fig.(3). 

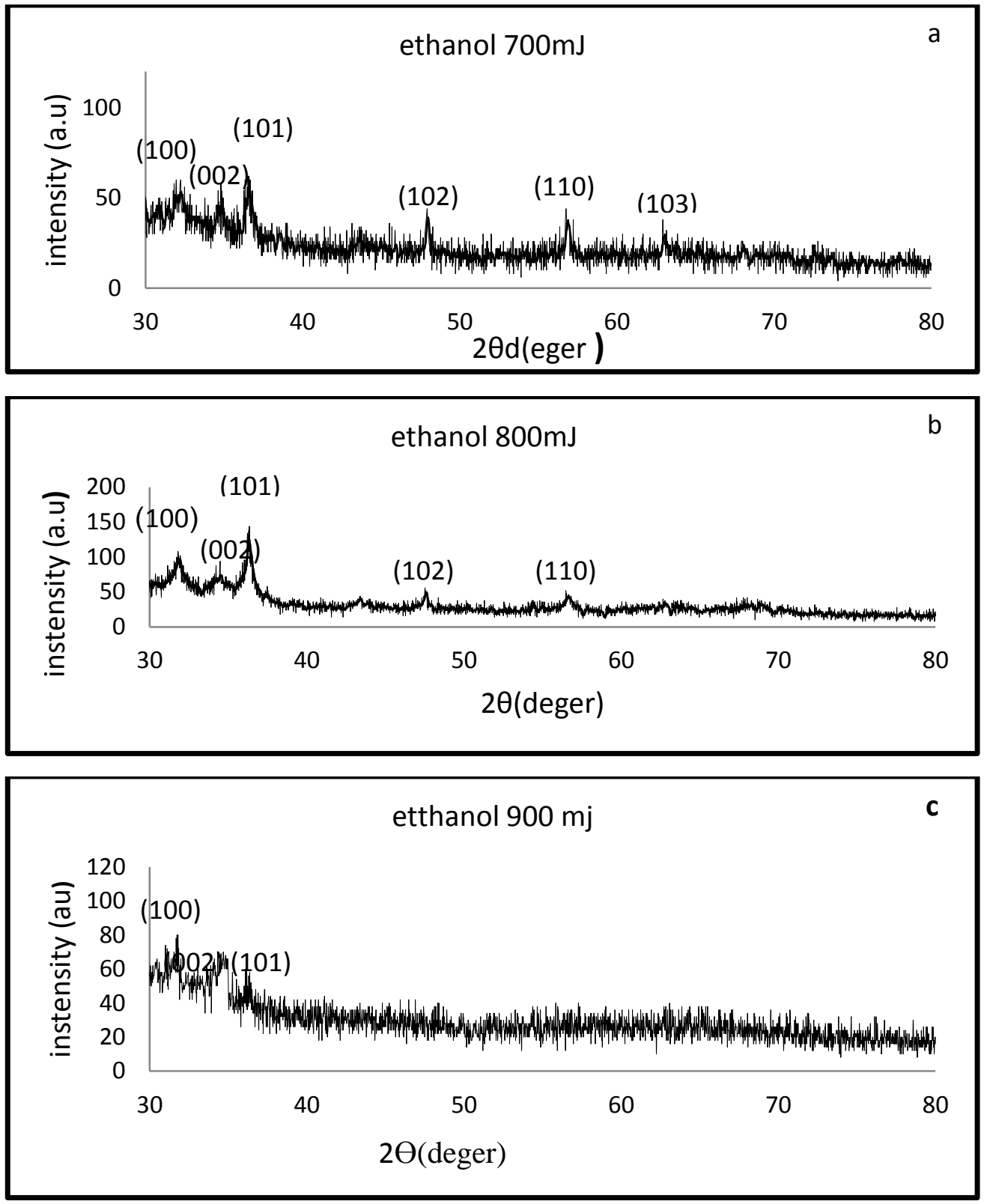

Fig. (3) : XRD pattern of ZnO NPs with different energies (a) $700 \mathrm{~mJ}(\mathrm{~b}) 800 \mathrm{~mJ}$ and (c) $900 \mathrm{~mJ}$ on glass substrate at 2000 puls.

Table (1)

The obtained results of the XRD of $\mathrm{ZnO}$ on glass substrate at different energy (700,800,900 $\mathrm{m} \mathrm{J})$ and fixed pulses at 2000.

\begin{tabular}{|c|c|c|c|c|c|}
\hline Ethanol/2000 & $\begin{array}{c}2 \theta \\
(\text { deg. })\end{array}$ & $\begin{array}{l}\text { Plane } \\
\text { (hkl) }\end{array}$ & $\begin{array}{c}\text { FWHM } \\
\text { (deg.) }\end{array}$ & $\begin{array}{c}\text { Crystal size (D) } \\
(\mathrm{nm})\end{array}$ & $\begin{array}{c}d \\
\left(A^{0}\right)\end{array}$ \\
\hline $700 \mathrm{~m} . \mathrm{J}$ & $\begin{array}{c}31.8 \\
34.62 \\
36.62\end{array}$ & $\begin{array}{l}100 \\
002 \\
101\end{array}$ & $\begin{array}{c}0.353 \\
0.15 \\
0.376\end{array}$ & 32.139 & 321.392 \\
\hline $800 \mathrm{~m} . J$ & $\begin{array}{c}31.1 \\
36.137\end{array}$ & $\begin{array}{l}100 \\
101\end{array}$ & $\begin{array}{c}0.165 \\
0.15\end{array}$ & 50.547 & 505.478 \\
\hline $900 \mathrm{~m} . \mathrm{J}$ & $\begin{array}{l}31.02 \\
34.02 \\
36.08\end{array}$ & $\begin{array}{l}100 \\
002 \\
101\end{array}$ & $\begin{array}{c}0.165 \\
0.13 \\
0.15\end{array}$ & 54.058 & 540 \\
\hline
\end{tabular}


Field emission scanning electron microscope (FESEM)

FESEM images confirmed that these NPs have different morphologies, it can reveal that the morphology of $\mathrm{ZnO}$ NPs is not uniform consist of many small irregular NPS.

In Fig.(4) shows SEM images of zinc oxide deposited on the glass substrate at temperature of $85^{\circ} \mathrm{C}$, at $700 \mathrm{~mJ}$ energy the shape is like flowers, But SEM images with energy $800 \mathrm{~mJ}$ and $900 \mathrm{~mJ}$ the shape seem clusters resembles balls of various sizes. with an average size shown in. Ethanol, in the energy $700 \mathrm{~mJ}$ seems the surface more uniform compared with others energies. On other hand, the images in $800 \mathrm{~mJ}$ and $900 \mathrm{~mJ}$ show irregular, big fragments and homogenous.
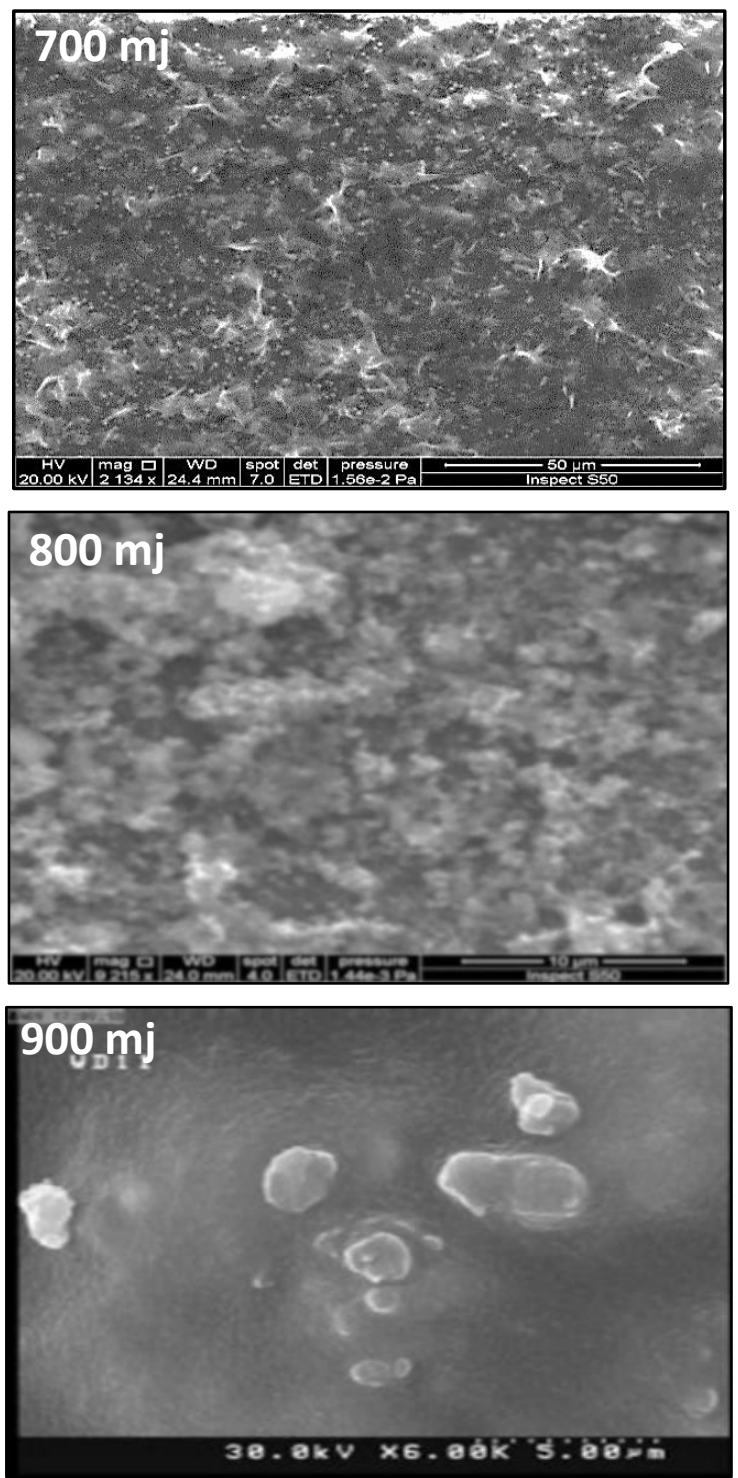

Fig.(4): FESEM images of $\mathrm{ZnO} \mathrm{NPs}$ prepared by pulsed laser ablation in ethanol with different energyies $(700,800,900 \mathrm{~m} . \mathrm{J})$ and pulses fixed (2000).

\section{Energy-dispersive X-ray spectroscopy}

Fig.(5) represent EDX spectra of the films contain the elements ( $\mathrm{Zn}$ and $\mathrm{O}$ ) indicating formation of the $\mathrm{ZnO}$ films with high purity. The elements ( $\mathrm{Au}$ and $\mathrm{Si}$ ) reveal the material in substrates, (silicon and glass).
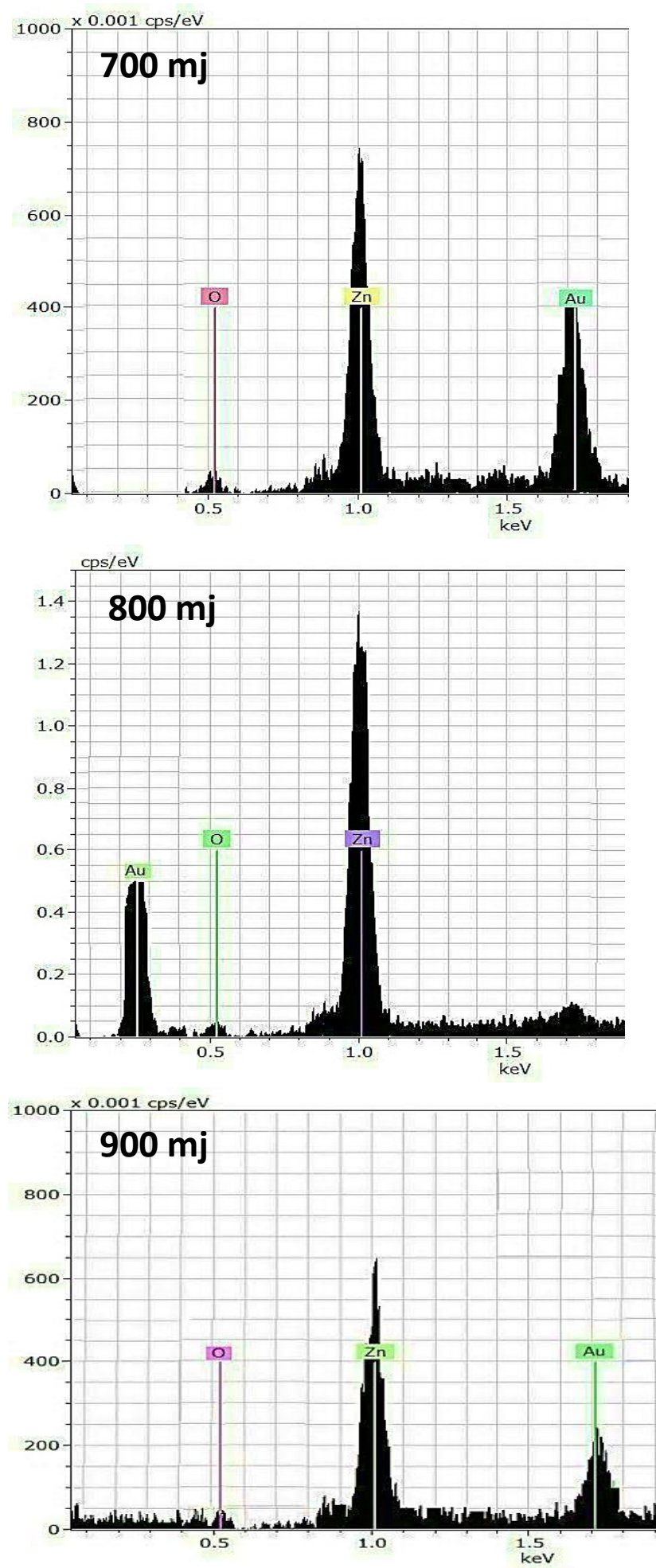

Fig.(5): EDX of $\mathrm{ZnO}$ thin films deposited on a glss substrate at 85 C for ethanol with different laser energies $(700,800$ and $900 \mathrm{~mJ})$. 


\section{Absorption}

The laser pulses parameters having an important effect on the formation of $\mathrm{ZnO}$ NPs show in Fig.(6) which tested by uv-vis at room temperature in the range $(300 \mathrm{~nm}$ to $900 \mathrm{~nm})$. For all the films, it is observed that the optical absorption increases due to increase in roughness with increasing the number of laser pulses, increased energy lead to increased absorpance thus will increased surface roughness. It is obvious that colors of liquids were changed differently within the process, it showed the fine bubbles formed in front of target after first $12 \mathrm{~min}$ of ablation. These bubbles apparently prohibited the laser energy to be absorbed by target. the maximum values observe at $(375,370$ and $365 \mathrm{~nm})$ of values of tion exponential as follows power $700 \mathrm{~mJ}$ was energies 700,800 and $900 \mathrm{~mJ}$ respectively.

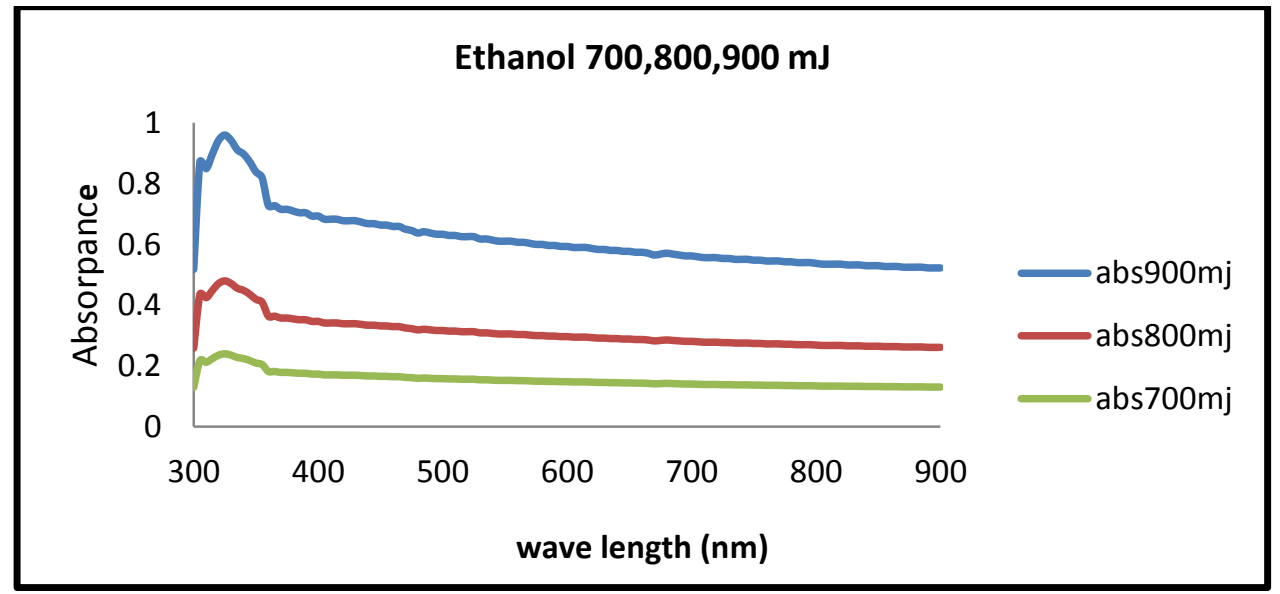

Fig.(6): Optical absorption as a function of wavelength for $\mathrm{ZnO}$ prepared on glass substrate with laser pulses of 2000 at different laser energies of $(700,800,900 \mathrm{~mJ})$.

\section{Optical energy gap}

The optical band gap decreases with increasing laser pulses, as showen in Fig.(7) ,The curves show shifts in the value of the band gap towards lower energy when increasing the laser pulses. This attributed to the increases in the crystal size with increasing laser energy. Where in the quantum confinement range, the band gap of the particle decreases as the crystal size increases, this behavior can be explained by the quantum confinement model [6]. This decrease in energy gap can be due to the prohibited impurities that led to the formation of donor levels with energy gap near the conduction band, which is in accordance with the findings of other workers [7]. At lower laser energy, a low number of $\mathrm{ZnO}$ NPs are ablated from the target as show in Table (2). The band gap reaches $3.25 \mathrm{eV}$ at $700 \mathrm{~mJ}, 3.40 \mathrm{eV}$ at $800 \mathrm{~mJ}$ and $2.95 \mathrm{eV}$ at $900 \mathrm{~mJ}$. 

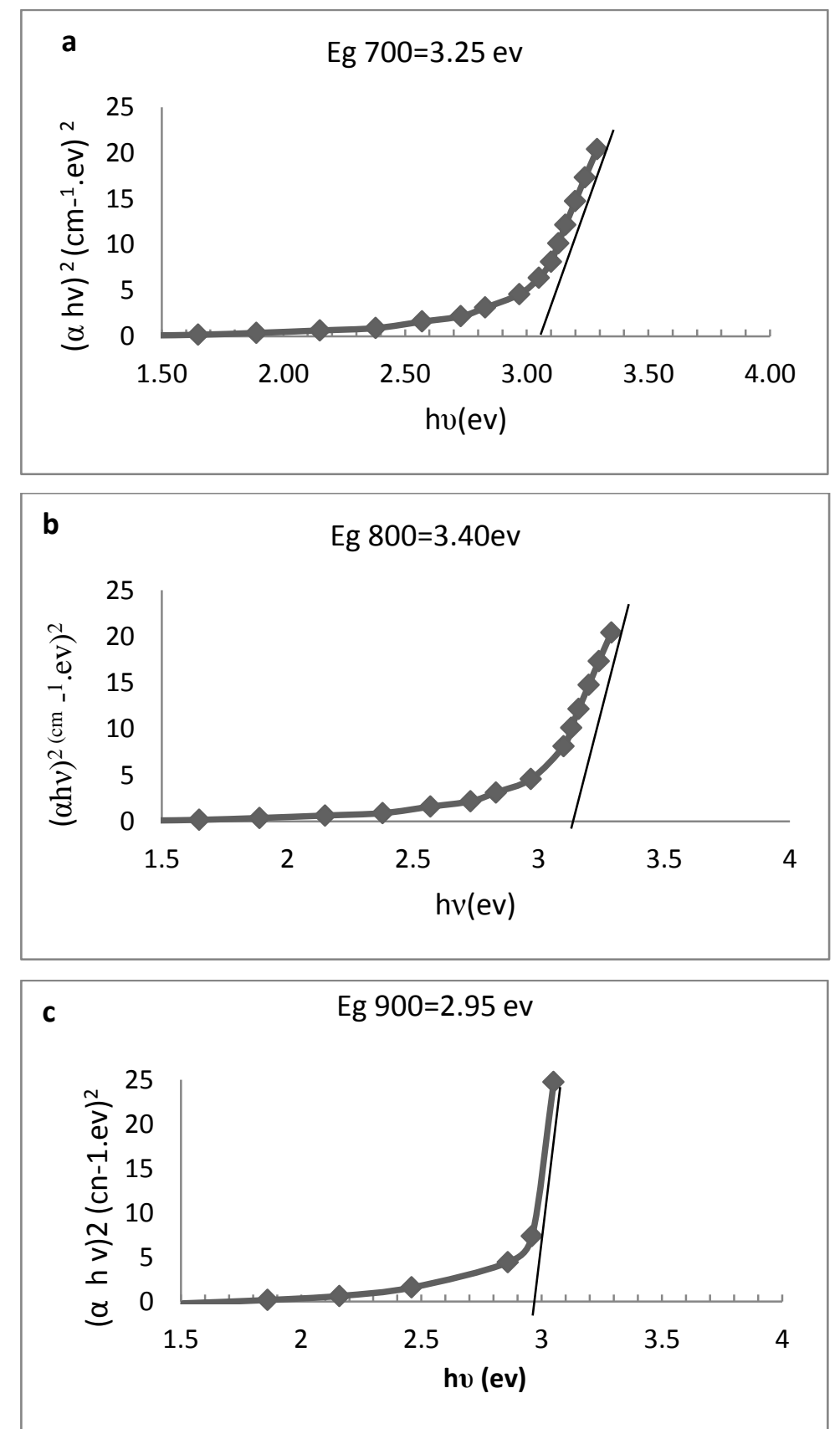

Fig.(7): Plot (ahv) ${ }^{2}$ versus hv of $\mathrm{ZnO}$ NPs prepare at different laser energies (a) 700 (b)800 (c) $900 \mathrm{~mJ}$.

Table (2)

Values of optical band gap as function of laser energy for ZnO NPs deponided on glass substrate.

\begin{tabular}{|c|c|c|c|c|}
\hline Solvent & No. of Pulses & Energies (mJ) & $\overline{E_{g}(e V)}$ & Wave length(nm) \\
\hline \multirow{3}{*}{ Ethanol } & \multirow{3}{*}{2000} & 700 & 3.25 & \multirow{3}{*}{325} \\
\hline & & 800 & 3.40 & \\
\hline & & 900 & 2.95 & \\
\hline
\end{tabular}

\section{Photoluminescence (PL)}

$\mathrm{PL}$ emission spectra of $\mathrm{ZnO}$ with different laser energies have been recorded at room temperature at excitations source of wave length of $325 \mathrm{~nm}$ as s shown in Fig.(8). The
PL spectrum of the pure $\mathrm{ZnO}$ exhibits stronge near-band-edge (NBE) emission at $382 \mathrm{~nm}$ and green luminescence band centered at about $492 \mathrm{~nm}$. The UV-emission typically results from the recombination of force of bound 
excitation indicating high crystal quality of the material wihle the green emission band originates from the recombination of photogenerated hole with a singly ionized defect. When using energy $(700 \mathrm{~mJ})$ and strikes in 2000 pulses there will be an increase in the spectrum of fluorescence to be $(368 \mathrm{~nm})$, while in the second form, which has been using the energy $(800 \mathrm{~mJ})$ it note a decrease fluorination in range $(371 \mathrm{~nm})$. But in energy $(900 \mathrm{mj})$ it note an increase in the spectrum of fluorescence value to be (377) $\mathrm{nm}$.
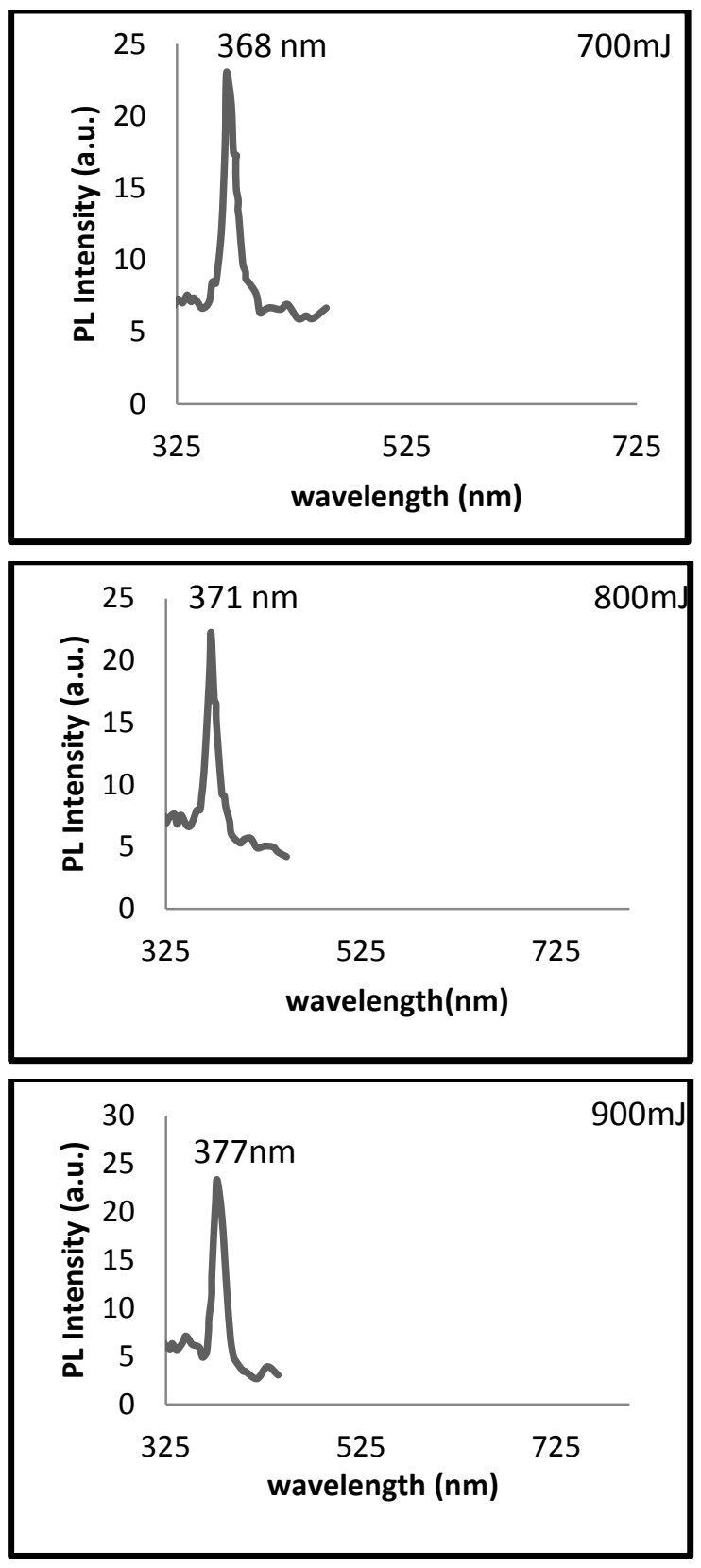

Fig.(8): PL spectra of $\mathrm{ZnO}$ NPs prepared at differences laser energies.
Table (3)

The photoluminescence measurements.

\begin{tabular}{|c||c|c||c||}
\hline $\begin{array}{c}\text { PL Intensity } \\
(\text { a.u. })\end{array}$ & $\begin{array}{c}\text { Eg } \\
(\mathbf{e v})\end{array}$ & $\begin{array}{c}\text { Emission } \\
\text { wavelength }(\mathbf{n m})\end{array}$ & $\begin{array}{c}\text { energy } \\
(\mathbf{m J})\end{array}$ \\
\hline \hline 304.22 & 3.2 & 368 & 700 \\
\hline 305.87 & 3.4 & 371 & 800 \\
\hline \hline 305.88 & 2.9 & 377 & 900 \\
\hline
\end{tabular}

\section{Conclusions}

Laser ablation in liquid provides a simple, flexible, controllable process and less expensive way for fabrication of $\mathrm{ZnO}$ nanoparticles. From the $\mathrm{X}$-ray characteristics for as prepared sample showed that amorphous structure of $\mathrm{ZnO}$ NPs films, but after annealing film $300^{\circ} \mathrm{C}$ show that is polycrystalline with hexoganal structure without any trace of an extra phase with preferential orientation in the (101) direction because the multiplicity of vertices of acte the direction. From SEM technique the formation rate $\mathrm{ZnO}$ nanoparticles suspensions, mean particle size could be controlled by proper selection of the laser parameters and liquid media. The NPs in liquids----have an almost perfect different shape, different flowers irregular shapes agglomerated and some presented chains of welded particles.

- Optical absorption spectra of -the sample prepared in ethanol at varying energy strong features in the UV range but have low absorption in visible region.

- The estimated band gap energy changes from (3.25 eVto $3.40 \mathrm{eV}$ and $2.95 \mathrm{eV}$ ) for nanoparticles suspension which is large and small than the bulk ( $3.4 \mathrm{eV})$ and is found to be decreased with increase in average crystal size of the prepared Nanoparticles.

\section{Reference}

[1] Qinghu You, Hua Cai, Kun Gao, Zhigao H, Shuang Guo, Peipei Liang, Jian Sun, Ning $\mathrm{Xu}$, Jiada $\mathrm{Wu}$, Highly transparent and conductive Al-doped $\mathrm{ZnO}$ films synthesized by pulsed laser co-ablation of $\mathrm{Zn}$ and $\mathrm{Al}$ targets assisted by oxygen plasma, Journal of Alloys and Compounds 626, 415-420, 2015. 
[2] T.W. Kim, D.U. Lee, D.C. Choo, J.H. Kim, H.J. Kim, J.H. Jeong, M. Jung, J.H. Bahang, H.L. Park, Y.S. Yoon, J.Y. Kim, J. Phys. Chem. Solids 63-881, 2002.

[3] M.A. Gondal, Q.A. Drmosh, Z.H. Yamani, M. Rashid, Synthesis of nanostructured $\mathrm{ZnO}$ and $\mathrm{ZnO} 2$ by laser ablation process using third harmonic of $\mathrm{Nd}$ :YAG laser, Int. J. Nanoparticles vol. 2009.

[4] Gao1,T. G. Meng, Y. Tian, S. Sun, X. Liu and L. Zhang "Photoluminescence of $\mathrm{ZnO}$ nanoparticles loaded into porous anodic alumina hosts" J. Phys.: Condens. Matter, 14, 12651-12656, 2002.

[5] Arash Baladi, Rasoul Sarraf Mamoory "Investigation of different liquid media and ablation times on pulsed laser ablation synthesis of aluminum nanoparticles" Applied Surface Science 256 7559-7564, (2015).

[6] S. Gnanam, V. Rajendran "Luminescence Properties of Eg-assisted $\mathrm{SnO} 2$ nano particles by sol-gel process", Digest Journal of Nano materials and Bio structures, Vol. 5, pp. 699-704, (2010).

[7] B. Zhang, Y. Tian, "Structural, Optical, Electrical properties and FTIR studies of Fluorine doped $\mathrm{SnO} 2$ films Deposited by Spray Pyrolysis", J. Mater Sci., 46, 18841889, (2011). 